\title{
Deviant Behavior in School Setting
}

\author{
Egemen Hanımoğlu \\ Correspondence: Egemen Hanımoğlu, The Faculty of Education, Cukurova University, Adana, Turkey.
}

$\begin{array}{lcc}\text { Received: July 9, } 2018 & \text { Accepted: August 28, } 2018 & \text { Online Published: August 29, } 2018 \\ \text { doi:10.11114/jets.v6i10.3418 } & \text { URL: https://doi.org/10.11114/jets.v6i10.3418 }\end{array}$

\begin{abstract}
Deviant behavior has become a daunting problem lately. More pupils are displaying abnormal behavior and thus destabilizing learning processes within school settings. It is a well-known fact that teenagers usually learn how to adapt to society and that aberrant behavior may lead to problems with conformity to societal values. Although the main causes of deviant behavior have been elucidated, the problem, despite numerous studies, deviant behavior has not been fully understood by scholars. The notion of deviance is closely related to the definition of the social norm which was defined almost a hundred years ago. The present study aims to examine causes and effects of deviant behavior, and identify main strategies to combat the issue. The research methods employed included a theoretical framework analysis, literature review, and qualitative research. A set of recommendations for the teenagers with deviant behaviour and their parents were identified to help them adjust to society.
\end{abstract}

Keywords: deviant behavior, school setting, social adaptation, social norms, causes and effects of deviant behavior

\section{Introduction}

In recent times, deviant behavior, which could be described as behavior that is different from the norm, has become a daunting global problem. In general, the word "deviant" (from Latin deviatio) means an abnormality (Collinsdictionary.com). Each year, the number of pupils with deviant behavior (also known as aberrant behavior) in general education schools steadily increases (Hayden, 2007; Damron-Bell, 2011). Aberrant behavior may not only lead to problems that include peer-pressure, bullying, and violence right within a school setting, but to also more serious consequences such as social maladaptation and crime (Rodger, 2008; Furniss, 2000).

The causes of aberrant behavior have not been completely determined to date. Therefore, this study set out to determine reasons for abnormal behavior exhibited by Turkish high-school students, the impact of deviant behavior on the school setting, and to recommend measures to children with aberrant behavior to adequately adapt to the society, and to teachers and parents measures to address the issue.

Social deviance has been investigated by numerous psychologists for over one century. Durkheim, Thomson, Vygotsky, Eisenstein amongst others, were the first scholars to address the issue (Goode, 2016). Social deviance inseparably mirrors socially-acceptable behavior (Vygotsky, 1934/1998). 'Social norms', can be interpreted as the limits or measures of conduct permissible within a society that ensure a society functions as it is should, and, most importantly, social norms help to preserve societies (Aitchison, 2012). According to Lapinski and Rimal (2005), human behavior may deviate either positively or negatively from socially acceptable norms. Positive deviance occurs when one's conduct does not harm anyone and appears as non-conformity. Negative deviance disorders established social systems and usually results in violence and crime. Positive deviance relates to creativity that brings positive changes to a society, whereas negative deviance is destructive and does not bring anything positive to a society whatsoever (Lapinski \& Rimal, 2005; Steinberg \& Morris, 2001).

Deviant behavior is defined by unorthodox traits that do not conform to officially established generally accepted social norms. Aberrant behavior causes negative evaluations e.g. crimes, to be committed by people. Deviant behavior has a destructive or self-destructive orientation characterized by persistence and repetition. Signs of deviant behavior include social exclusion and self-identification as deviant in terms of age and gender. It is very important to differentiate aberrant behavior (wrongful and immoral) from character traits like strangeness, eccentricity, eccentricities, available individuality, which are not harmful (Goode, 2016).

Deviant behavior poses a real threat to the physical and social survival of an individual within certain social environments or collective settings. Deviations are marked by violation of social norms, moral norms, cultural values, 
the process of assimilation, and in the reproduction of values and norms. It may stem from a single action by an individual that does not meet set out social norms. E.g. the criminalization of society, divorce, corruption of officials etc. The concepts of 'norm' and 'deviation' are socially defined (Shaffer, 2009). In medicine, aberrant behavior relates to deviation from generally accepted norms that guide interpersonal interactions. Within the framework of mental health and frontier state, these actions, acts, statements describe forms of neuropsychiatric pathology (Goode, 2016). In psychology, deviant behavior is defined as a deviation from socio-psychological and moral norms (Goode, 2016). Deviations are characterized by violation of socially accepted norms that cause damage to individuals themselves, public welfare, and their surroundings.

Aberrant behavior can be regarded as a choice between socially acceptable and deviant ways of achieving set goals (Sherif, 2005). For example, when trying to get rich or attain success (as defined by oneself), one may choose unacceptable means e,g., bullying others or even engaging in criminal activities (Dwyer, 2016). Others may portray open disobedience, protest, reject widely accepted social values including moral and legal laws, and unite in participating in various criminal, terrorist or other extremist groups. Therefore, they choose to combat the society they live in rather than try to fit in (Graham, 1988; Hall \& Hayden, 2007; White, 2016). In all these cases, the aberration results from a complete or relative failure of socialization i.e. the inability or reluctance of individuals to adjust to society and its requirements,

Deviant behavior by teenagers includes antisocial, delinquent, wrongful, aggressive, self-destructing, and suicidal acts. These acts may lead to various abnormalities in personal development. Often these deviations include children's reactions to the difficult life circumstances (Wolfe, Marcum, Higgins \& Ricketts, 2014). This condition often ranges from facets of disease to norm. Therefore, it should be evaluated by both a teacher and a doctor.

The causes of deviant behavior are related to conditions of upbringing, peculiarities of physical development and one's social environment. The teenager, evaluating his or her body, takes note of the norm, his physical superiority or inferiority, and comes to a conclusion about his or her social significance and value (Berdibayeva, Garber, Ivanov, Satybaldina, Smatovad \& Yelubayeva, 2016). A child may either have a passive attitude to his or her physical weakness, or a desire to compensate for deficiencies, or a willingness to eliminate them by physical exercise. Sometimes delays in the development of neuro-muscular function disrupts coordination of movements and manifests as clumsiness.

Reproaches and slight comments by others concerning their appearance and awkwardness provoke violent affections and distort their behavior. Tall boys are confident in their strength and manhood and do not need to fight to earn the respect of their peers (Zotova, Prjazhnkikov, Berezhnaja, Ermakov \& Melamud, 2016). Thus they are more obedient, natural and need less attention. Thanks to their self-confidence, other children perceive tall boys as being very sensible. Skinny, developmentally-deficient, stunted boys are perceived by others as immature, small and unfit. Such boys need custodial supervision because they are rebellious. To change such unfavorable perceptions about themselves, they ought to show entrepreneurial ingenuity, courage, exemplary personal achievements and be constantly present in order to prove their usefulness and indispensability among their peer-groups (Zotova et al., 2016). This activity provokes emotional tension and difficulties in communication, which are ideal conditions for violation of generally accepted standards.

Teenage deviant behavior often has social causes, for instance, disadvantages in education and upbringing. Delinquency shoots from the house in most cases. The very first shoots of deviance are carried out due to fear of punishment, or as a protest, which then turns into a reflex-like stereotype (Denzin, 2010). The causes of the deviant and delinquent behavior in teenagers stem from lack of supervision, lack of attention from relatives, fear of punishment, dreaminess, the desire to eliminate the guardianship of caregivers or parents, ill-treatment by comrades, and in an unmotivated thrust to change the status quo. Vagrancy may also lead to delinquency.

On a separate note, early alcohol and drug abuse among teenagers is motived by a desire to be in the company of adults, feel mature, to satisfy curiosity, or change the prevailing mental state. Following alcohol consumption, there is a cheerful mood, increase in self-confidence, and disinhibition (Berdibayeva et al., 2016). Group addiction that emerges when drinking with friends is likely to lead to alcoholism.

As a rule of thumb, the initial and often only factor that promotes social adaptation of teenagers with deviant behavior is an external requirement by society to conduct themselves in such a way that they are in compliance with regulations and norms (Tankard \& Paluck, 2016). However, this external requirement does not lead to positive emotional reactions (Van Zoonen, 2013). Thus, the teenager does not have an internal motivation for social adaptation. The school's responsibility is to present this external requirement to deviant teenagers. Rubington and Weinberg (2015) however, believe that this is contradictory as the normative state fixes this responsibility with parents. Nevertheless, in practice, the basic role of educational facilities, i.e., schools, is to educate children and teenagers. In our opinion, this is due to the inability of the family to assume such a burden due to material difficulties, and a limited understanding of the 
developmental processes of teenagers, etc. (Gonen, Sharon, Pearlson \& Hendler, 2014). By being in interaction with others as they grow and learn, individuals either completely or partially accept, or absolutely deny life values promoted by educational facilities (Boxford, 2006). Positive social adaptation occurs when the life of the school's team is saturated and attractive, and creates opportunities for communication with peers and the desire for this communication (Hayden, 2007).

Children with abnormal behavior in society, in most cases, reside in families where either there is no second parent, or this social cell is dysfunctional, therefore, they need special assistance to coordinate their behavior.

Such children cannot physically or psychologically cope with their problems (Wilson \& Deane, 2010). Thibaut (2017), suggests that teenagers, in their essence, are extremely vulnerable and resentful. If a child lacks parental care and warmth, he or she chooses a protective reaction in the form of alienation (isolation, unsociability, coldness, neglect, emotional instability, etc.) Societal factors that manifest in the shortcomings of schools, the public or the family are also responsible for children's behaviour. It is not a secret that in unfavorable families, children (and not only children), are subjected to ill-treatment or violence at home, school, and outdoors (Jones, 2016). Ill-treatment is not always limited to the physical realm; it may also present as emotional violence that causes no less harm to the child's mental and physical health than other forms of violence (Swann \& Bosson, 2010). Parents, who are unaware of the negative consequences of ill-treatment, only worsen the situation for their children when they try to 'educate' them (Boxford, 2006). The reaction of a child or teenager will depend on his or her age, experience and character. However, it is interesting to note that children exposed to ill-treatment often become abusive to their own their children similar to what they experienced in childhood (Hall \& Hayden, 2007). Socio-economic challenges are determined by 'classes' of the society, which are poor and rich (Zorrilla, Pires, Lasheras, Morant, Seoane, Sanchez \& Durbán, 2010; Swann, Rentfrow \& Guinn, 2005). Moral and ethical challenges are initially caused by inadequate cultural and spiritual development of society (Gauffin, Vinnerljung, \& Hjern, 2015). Subsequently, this leads to an indifference to teenage deviant behavior in disregarding family, school, and society at large.

So far, we have delved into the main issues related to deviant behavior. Aberrant behavior by school pupils undoubtedly requires an adequate response. In modern pedagogy there are three ways to address this: social psychological rehabilitation, social and pedagogical prevention and psychological and pedagogical support.

\section{Focus of the Study}

This research study investigated the causes and effects of deviant behavior among a group of high-school students, aged 14-18 years within a school setting in order to provide baseline information for future studies. The group was formed after asking teachers and parents to identify students with obviously aberrant behavior. A set of recommendations was also provided based on the study findings for schools' administration as well as parents to adequately address this issue.

\section{Research Methodology}

\subsection{Study Design and Population}

To assess deviant behavior in a high-school setting and ways in which students choose to adjust to the society (if they do), a qualitative research approach was chosen. This approach was deemed more suitable to study a relatively small group of people consisting of only 42 members. Notably, the qualitative approach requires diverse data collection methods to achieve the desired results (Hsieh \& Shannon, 2005). As a result, the researcher utilized psychological testing and interviewing to ensure that the gathered results were adequate. Three schools in Adana were randomly chosen to participate in the study. These included Adana Anatolian High School, Şehit Temel Cingöz Anatolian High School, and ÇEAŞ Anatolian High School.

\subsection{Study Interviews}

Initially, interviews were conducted with teachers and, parents of students that exhibited deviant behavior. The students were first asked to consent to participate in an anonymous survey specifically designed for this study. The students were then given a 17-item questionnaire with open-ended questions. To systematically analyze the obtained responses, Smith's (1992) recommendations were employed. The collected results were then systemized and processed. The outcomes of the analysis are presented later in this article.

\subsection{Data Collection Tools}

This study utilized the 'survey method' to collect data. It should be understood that in all forms of this method, the aim of the investigator is expressed in the form of a hypothesis (or hypotheses), the signs whose presence or absence allow the investigator to conclude the sincerity and reliability of answers obtained. Among such signs include the behavior of interviewees, for example, interested, active answers, or, on the contrary, the desire to avoid the response, involuntary pauses, features of facial expressions and gestures, the nature of behavior, emotional reactions (i.e., nonverbal 
information). According to American Psychological Association, when using a survey, it is very important to have a clear and straightforward statement of the question. Questions should not imply the desired answer, and some questions should not be posed directly. The study utilized a self-administered questionnaire, designed by the researcher. Participants (students) were told to anonymize their responses to encourage honesty (Baranauskas, 2014). The questionnaire had only open-ended questions, which are suitable for qualitative data collection as they give the respondents the freedom to indicate their responses and explain them adequately. Bird (2009) contends that a questionnaire is a basic and popular tool for harnessing information regarding perceptions about natural issues and public knowledge. An inquiry form helps the investigator to garner valuable data to analyze the phenomenon under consideration. Bird (2009) maintains that questionnaires are established tools in social sciences studies that are intended to acquire information about social features of participants, past and present behaviors, attitudes and standards of behaviors, beliefs as well as reasons for their respective actions in line with the topic investigated (Babbie, 1992).

\subsection{Psychological Testing}

In psychological testing, tests are always connected with the measurement a psychological phenomenon and the estimation of its level of development or formation. Therefore, the quality of the dough is important (Catanzaro, 1988). The test is characterized by its accuracy, i.e., reliability and validity. The reliability of the test is the extent to which the obtained indicators are stable and not dependent on random factors (Nassaj, 2015). Reliability refers to comparing the testimony of the same subjects. This means that a robust test must provide consistent test results during re-testing.

\subsection{Literature Review}

A literature review of deviant behavior and the main reasons for its occurrence was an integral part of the study. After having formulated the aims and objectives of this study, relevant scientific literature was analyzed to describe the theoretical framework and basis of the study. The study of literature, documents, materials on electronic media and other sources as means of obtaining facts characterizing the history and current state of the object being studied, serves as a way of creating initial perceptions of the original concept of the subject of research, the detection of white spots, and ambiguities in the development of the issue . Careful study of literature helps to separate the known from the unknown, to identify established facts, accumulated experience, and clearly outline the problem being investigated (Coffey \& Atkinson, 1996). Google Scholar and Research Gate were accessed and the following key words used to conduct the search: deviant behavior, deviant behavior in a high-school setting, the notion of social norm, social adaptation.

The following criteria were used to select literature sources to include: publication date, scientific importance, experimental nature of the study, number of citations by other researchers, and relevance to the present research. Subsequently, a number of scientific literatures (both theoretical and experimental) were chosen to develop the theoretical framework for the present study. The materials were critically assessed to decide whether they were suitable for the present study or not, and only those that did, were included in the corresponding section. Based on literature review, it was possible to come up with a set of recommendations thus fulfilling the aims of this research.

\subsection{The Phenomenological Approach}

This approach was chosen to study individual experiences of each participant. The descriptive approach proposed by this approach deliberately rejects pre-formulated hypotheses and concepts, which in the natural sciences are an essential auxiliary tool for grasping reality (Davidsen, 2012). The main task in the phenomenological research approach is a mutual, subjective perception of the meaning of an individual experience, and the reciprocal understanding between the researcher and the participant of the meaning of an individual experience (Scollon, 2018). The basic idea is to examine the subjective experience of a participant and to try to see it from his or her point of view to determine possible solutions.

\subsection{Reliability and Validity}

Due to relatively small group of participants (42 persons), the results were not generalizable to a wider group of people. As argued by Noble and Smith (2015), qualitative research may lack validity and reliability due to several factors that include the researcher's subjective biasness and unclear justification of adopted methods (Noble \& Smith, 2015). To guarantee reliability and validity of the present study, several techniques were used during data collection from survey participants.

Firstly, the questions were clear for ease of understanding by participants. Questions were designed to address exactly what they were examining (causes and effects of deviant behavior, and how students cope with situations caused by aberrant behavior). The questionnaire was also checked for the presence of leading questions that could potentially lead to biased results. The researcher consulted experts in the field of psychology to review questionnaire. Finally, a 'pilot study' was conducted to pretest the questionnaire for ease of comprehension among potential respondents (McLeod, 2014b). 


\subsection{Ethical Issues}

An investigation that includes human interaction to obtain information requires the application of moral and ethical standards. The researcher obtained participants' informed consent to participate prior to participation. Participation was entirely voluntary and participants were free to decline to answer any questions. The questionnaire however was designed in a way to limit the possibility on 'inconvenient questions'. The data gathered was kept private and was not shared with third parties.

\section{Findings}

The survey was quantitatively analyzed and percentages for the responses were obtained. The findings from the data of the 42 respondents are as follows:

Responsibility for deviant behavior: The majority of the respondents $(74 \% ; 18 \%$ male and $56 \%$ female) felt responsible for their own actions and considered themselves independent when it came to decision-making.. The remaining $26 \%$ felt that their actions were influenced by other people. The majority of the participants associated deviant behavior with alcohol use.

Alcohol consumption: 38\% (16 participants; 14 male and 2 female) consumed alcohol. When asked why they consumed alcohol, 12 out of them said it was for fun while 4 of them said they resorted to alcohol when they were stressed. Overall, only 40\% (17 respondents) felt that drinking of alcohol by young people was a major cause of deviant behavior.

Smoking: When asked whether they smoked, $16 \%$ (all male) of respondents indicated that they smoked when with their peers. None of the female participants smoked since they associates the habit with being rebellious to societal norms. Out of the 42 interviewed, 40 feel that smoking was a bad habit while 2 of them felt that it wasn't.

Consumption of other illicit drugs: None of the sampled participants indicated that he/she was a drug addict. $76 \%$ of the participants were against drug use and addiction and argued that the habit affected physical, mental, and psychological health.

Suicide attempts and bullying: Out of the 42 participants, $38 \%$ said they had thought about suicide at some point in their lives while $8 \%$ had tried it at one point in their lifetime. In addition, $36 \%$ of the respondents felt that committing suicide was a great weakness and that students should opt for counseling instead.

Computer games: According to the analysis, $65 \%$ said that they loved computer gaming although they did not consider it a deviant behavior.

Social Media: Out of the sampled 42 respondents, $87 \%$ associated the media with deviancy due to the content posted especially if it was uncensored. $3 \%$ said that they watched pornographic content through their gadgets such as mobile phones and tablets as the videos and images were readily available on the net. However, they accepted that such behavior contradicted the society's norms as it eroded morals.

\section{Recommendations on how to address deviant behavior from review of literature}

Key findings from the systematic review of literature concurred with research findings found from the qualitative survey. Furniss (2000), analyzed whether bullying in schools was considered a crime. The research is in concurrence with findings from the survey that bullying colleagues is one of the impacts of aberrant behavior in students. Boxford (2006) also analyzed crime in schools, which is part of deviant behavior in many students. Some theories such as functionalism have enabled understanding of deviant behavior from different perspectives. In this case, analyzing the literature was useful in this study, as it supported survey findings. The literature also supported the family unit as one of the foundations of behavior in children and provided a link between labeling somebody as deviant with actualization of unacceptable conduct.

\section{Discussion}

Study findings helped to single out the most spread forms of deviant behavior among students. In the course of the study, the main causes of deviant behavior also were determined. It is evident that the causes of deviant behavior among students lie in peculiarities of interconnection and interaction of the person with his or her surrounding world, and social environment (Lewis \& Frydenberg, 2004). Three main causes of deviant behavior are biological, psychological and social. The biological causes are expressed in the physiological peculiarities of the teenager, i.e. their impairments. The psychological cause lies in the peculiarities of their temperament, accentuation character. Whereas the social causes reflects the interaction of the teenager with his or her society, family, and school. Thus, among the causes of deviant behavior, many researchers distinguish heredity, social environment, education, upbringing, and individual social activity. Although all of these factors have direct or indirect effects, there is no direct relationship between their negative effects and the nature of a child's behavior. 
The most common form of deviant behavior among students was alcohol consumption: $82 \%$ of respondents used alcoholic beverages for company or fun and considered it normal despite most of them (58\%) stating that there were no positive aspects of alcohol consumption.

An infrequent form of deviant behavior among students was smoking-only $36 \%$ of those surveyed smoke. Students did not consider smoking a fashionable norm or phenomenon. Notably, it was encouraging that most of students did not use drugs or other psychoactive substances $(82 \%)$. They found it unacceptable to students, and the majority (80\%) of respondents did not find drug addiction to be of any benefit.

Deviant behavior, such as suicide, was not common among students: of $38 \%$ of respondents who had thought about the suicide, only $14 \%$ had tried to commit suicide. Students saw the main cause of suicide as conflicts and undivided love. Most students considered suicidal acts to be unfortunate events among weak people. I believe that suicide is uncommon among students, because young people find other ways to overcome difficult psychological situations.

Computer gaming was not common among students; only $40 \%$ of the students were interested in computer games, but considered it a waste of time and spent no more than 2 hours a day on computer games.

Deviant behavior which is associated with violence in schools and could therefore be prevented by dealing with the identified causes.

\section{Conclusion and Recommendations}

From the survey, it was clear that alcohol consumption and smoking were the two issues that needed to be addressed to prevent teenagers from doing harm to themselves or other people.

The premise on which deviant behavior is defined relates to a direct characteristic of one or other abnormality. Delinquent behavior is characterized by a blurred view of existing legal order and norms (Uski \& Lampinen, 2014). It manifests in petty and large-scale offenses, accompanied by outbreaks of aggression. In parallel, there may be attempts to protest specific actions or instructions which is expressed in actions, words or hobbies. On the background of such behavior, a low social intellect is often observed, and problems with adaptation are often present. Typical symptoms range from craving for quick and easy enjoyment, giving up on studying and absence of motivation to work.

A typical characteristic of delinquent behavior in children and teenagers is an unhealthy dependence on the one's mother. The mother is perceived as an ideal model even when she enacts negative actions against the child. Addictive behavior can also manifest and coexist with this type of deviant behavior. It is characterized by unhealthy dependencies of different types that manifest both at the physiological and psychologically levels. Dependent people often poorly tolerate loneliness, and are therefore vulnerable to external influences.

Psychopathological behaviors are typical traits of mental abnormality. The "main features" and "products of disease" (e.g. delusions, hallucinations, illusions, affective ideas) may both appear in this instance.

A destructive form of deviant behavior manifests with the aid of internal or external aggression. This can be typical e.g. vandalism, violence, or present as different forms of addictions, as well as suicidal tendencies.

To attain the status of adulthood, adolescents have to cope with a number of challenges related to the stage of life-course development. For various reasons, deviant behavior often occurs in adolescence.

Prevention of deviant behavior among teenagers consists of the formation of a healthy attitude towards themselves, their surroundings, and developing a healthy way of life. It is necessary to, pay attention to teenagers during this period, communicate with them, discuss their problems and try to solve them together. An important preventive measure is removing children from asocial families (alcoholics, drug addicts, homeless, etc.) as early as possible.

Correction of deviant behavior among teenagers ought to be carried out both by parents, and professional psychologists in individual or group settings using various methods e.g. destruction of a negative type of a character, adjustment of a motivational sphere and self-consciousness, stimulation of positive behavior, etc.

Progressive increase in deviant behavior, and the inevitability placed on society, prompt social service and social teachers to search for forms, methods and technologies to work with teenagers who fail to socialize. Efforts are usually directed to both rehabilitation of the child and prevention of deviation from social norms, i.e. the elimination of conditions that directly or indirectly negatively impact on the actions of the minor. Therefore, in science and in practice, the basic technology for prevention of formation of deviant behavior among teenagers is largely preventive.

'Prevention' is a set of state, social, medical and organizational and educational activities aimed at forestalling, eliminating or neutralizing the main causes and conditions that cause various kinds of social deviations in human behavior. It is based on the fact that teenage deviant behavior occurs because minors simply do not know them. Therefore, the state and society should inform minors about their rights and obligations, and the requirements to fulfill 
the social norms set for their age group. This can be done through the mass media (print, radio, and television), cinema, theatre, fiction and other cultural works, as well as through a system of social education. This will develop and educate the consciousness of the teenager and aide in assimilation of moral norms of behavior congruent to that of the society.

The social and preventive approaches consider the identification, elimination and neutralization of causes and conditions that cause different kinds of negative phenomena. The essence of these approaches are the systems of socio-economic, social and political, organizational, legal and educational activities, carried out by the state, society, or a specific social and pedagogical institution, social educator etc. to eliminate or minimize the causes of deviant behavior.

Thus, the absence of targeted information on the consequences of deviant behavior (for example, the use of drugs), leads minors (and adults too) who consume them, to criminal responsibility. With the adoption of the new Law on Narcotic drugs and psychotropic substances, both those that distribute and use drugs are liable to criminal prosecution.

An equally important problem in our society is the prevention of alcoholism, as well as informing teenagers about the real social and psycho-neurological consequences of drunkenness and alcoholism. The lack of preventive work, for example, with future parents, leads to an increase in children born with severe physical and psychological abnormalities, especially among young mothers, who do not know the elementary rules of behavior during pregnancy and therefore do not abstain from taking alcoholic beverages during pregnancy.

Among the main methods of addressing deviant behavior, prevention using a medico-biological approach along with information and socio-preventive approaches are of utmost importance. Its' essence consists of purposeful measures of medical-prophylactic character for persons suffering from various psychic anomalies, i.e. pathology at a biological level.

It is well known that a sane man can refrain from criminal actions with the help of his volitional qualities, moral norms and values. A person with a pathology in mental health and development (also known as insanity), can violate the existing moral and legal norms due to his psychophysiological peculiarities. It is very important to recognize a teenager with various pathological disturbances of the psyche that can lead him or her to commit rash actions. A psychiatrist should examine a teenager; provide appropriate medical treatment, supplemented by the educational influence of social conditioning. The social pedagogical approach consists of restoration or correction of moral and volitional qualities of personality in a person with deviant behavior.

Prevention of deviant behavior should include monitoring of risk factors for deviant behavior. Often the preconditions for deviant behaviors lurk in the family. A family inculcates in a child, basic values, behavioral stereotypes and norms. The emotional sphere of the child's psyche is formed in the family. Defects that occur due to home education are therefore very hard to fix. However, based on our recommendations, the influences of parents on children's personality are collapsed to a minimum. Depending on when the deviation occurred, correctly rendered psychological help can prevent the deformation of a teenager's personality.

Prevention of deviant behavior includes measures of general prevention and measures individual prevention. General prevention measures involve all students in a school and prevent the failure of all students from developing into socially responsible citizens. Measures of the special prevention provide an opportunity to identify children in need of particular pedagogical attention and conduct remedial work at the individual level. These inlcudes such elements: identification and registration of children in need of particular attention; reason analysis of deviant behavior; and defining and implementing corrective measures.

\section{References}

Aitchison, J. (2012). Words in the Mind: An Introduction to the Mental Lexicon. John Wiley \& Sons.

American Psychological Association (n.d.) Understanding psychological testing and assessment. Psychology Help Center, Retrieved from http://www.apa.org/helpcenter/assessment.aspx

Babbie, E. (1992). The Practice of Social Research. New York: Macmillan.

Baranauskas, M. C. C. (2014). Social awareness in HCI. Interactions, 21(4), 66-69. https://doi.org/10.1145/2621933

Berdibayeva, S., Garber, A., Ivanov, D., Satybaldina, N., Smatovad, K., \& Yelubayeva, M. (2016). Identity crisis' resolution among psychological correction of deviant behavior of adolescents - Procedia. Social and Behavioral Sciences, 217, 977-983. https://doi.org/10.1016/j.sbspro.2016.02.077.

Bird, D. K. (2009). The use of questionnaires for acquiring information on public perception of counselling - a review of current knowledge and practice. Journal of Psychological Counselling, 9, 1307-1325.

Boxford, S. (2006). Schools and the Problem of Crime. Cullumpton/Devon, Willan Publishing. 
Catanzaro, M. (1988). Using qualitative analytical techniques. In N. F. Woods \& M. Catanzaro (Eds.), Nursing Research: Theory and Practice (pp. 437-456). St. Louis, MO: C. V. Mosby.

Coffey, A., \& Atkinson, P. (1996). Making Sense of Qualitative Data: Complementary Research Strategies. Thousand Oaks: Sage.

Damron-Bell, J. (2011). The development of deviant behavior in adolescents: the influence of student characteristics and school climate. Electronic Theses and Dissertations, Paper 309.

Davidsen, A. S. (2012). Phenomenological approaches in psychology and health sciences. Qualitative Research in Psychology, 10(3), 318-339. https://doi.org/10.1080/14780887.2011.608466

Denzin, N. K. (2010). Rules of conduct and the study of deviant behavior: Some notes on the social relationship. In M. McCall (ed.) Friendship as a Social Institution, 62-95. New York: Routedge.

Dwyer, A. (2016). Youth gangs, violence and social respect: Exploring the nature of provocations and punch-ups [Review of the book by Rob White] International Journal for Crime, Justice and Social Democracy, 5(4), 154-156. https://doi.org/10.5204/ijcjsd.v5i4.364

Furniss, C. (2000). Bullying in schools: It's not a crime - Is it? Education and the Law, 12(1), 9-29. https://doi.org/10.1080/713667559

Gauffin, K., Vinnerljung, B., \& Hjern, A. (2015). School performance and alcohol-related disorders in early adulthood: A Swedish national cohort study. International Journal of Epidemiology,44(3), 919-927. https://doi.org/10.1093/ije/dyv006

Gonen, T., Sharon, H., Pearlson, G., \& Hendler, T. (2014). Moods like ups and downs of the motivation pendulum: Revisiting reinforcement sensitivity theory (RST) in bipolar disorder. Frontiers in Behavioral Neuroscience, 8 , 378-390. https://doi.org/10.3389/fnbeh.2014.00378

Goode, E. (2016). Deviant Behavior (11th ed.). New York: Routledge.

Graham J. (1988). Schools, disruptive behavior and delinquency. Home Office Research Study, 96, London: HMSO.

Hall, N., \& Hayden, C. (2007). Is 'hate crime' a relevant and useful way of conceptualising some forms of school bullying? International Journal on School Violence, 3, 3-24.

Hayden, C. (2007). Children in Trouble, the Role of Families, Schools and Communities, Basingstoke: Palgrave/Macmillan.

Hsieh, H. F., \& Shannon, S. E. (2005). Three approaches to qualitative analysis. Qualitative Health Research, 15, 1277-1288. https://doi.org/10.1177/1049732305276687

Jones, O. (2016). Anger management. Owen Jones

Lapinski, M. R., \& Rimal, R. N. (2005). An Explication of Social Norms, Communication Theory, 15(2), 127147, https://doi.org/10.1111/j.1468-2885.2005.tb00329.x

Lewis, R., \& Frydenberg, E. (2004). Adolescents least able to cope: How do they respond to their stresses? British Journal of Guidance \& Counselling, 32(1), 25-37. https://doi.org/10.1080/03069880310001648094

McLeod, S. A. (2014b). Questionnaire. Retrieved from www.simplypsychology.org/questionnaires.html

Nassaj, H. (2015). Qualitative and descriptive research: Data type versus data analysis. Language Teaching Research 2015, 19(2), 129-132. https://doi.org/10.1177/1362168815572747

Noble, H., \& Smith, J. (2015). Issues of validity and reliability in qualitative research. Evidence-Based Nursing, 18, 34-35. Retrieved from http://ebn.bmj.com/content/18/2/34

Rodger, J. J. (2008). Criminalising Social Policy. Anti-Social Behavior and Welfare in a De-civilised Society. Cullumpton/Devon: Willan Publishing.

Rubington, E., \& Weinberg, M. (2015). Deviance: The Interactionist Perspective (10th ed.). New York: Routledge.

Scollon, C. N. (2018). Research designs. In R. Biswas-Diener \& E. Diener (Eds), Noba textbook series: Psychology. Champaign, IL: DEF publishers. Retrieved from http://nobaproject.com/modules/research-designs

Shaffer, D. R. (2009). Social and Personality Development. Belmont, CA: Wadsworth.

Sherif, M. (2005). Group Conflict and Cooperation. Their social Psychology (1st published in 1967). London: Routledge.

Smith, C. P. (Ed.). (1992). Motivation and Personality: Handbook of Thematic Content Analysis. Cambridge University 
Press. https://doi.org/10.1017/CBO9780511527937

Steinberg, L., \& Morris, A. S. (2001). Adolescent development. Annual Review of Psychology, 52, 83-110. https://doi.org/10.1146/annurev.psych.52.1.83

Swann, W. B., \& Bosson, J. K. (2010). Self and identity. In: Fiske, ST, Gilbert, DT, Lindzey, G (eds) Handbook of Social Psychology. 5th ed. Hoboken, NJ: John Wiley \& Sons, Inc., 589-626. https://doi.org/10.1002/9780470561119.socpsy001016

Swann, W. B., Rentfrow, P. J., \& Guinn, J. S. (2005). Self-verification: The search for coherence. In: Leary, M.R. \& Tangney, J.P. (eds) Handbook of Self and Identity. New York: Guilford Press, pp. 367-383.

Tankard, M. E. \& Paluck, E. L. (2016), Norm perception as a vehicle for social change. Social Issues and Policy Review, 10: 181-211. https://doi.org/10.1111/sipr.12022

Thibaut, J. W. (2017). The Social Psychology of Groups (1st published in 1987). New York: Routledge.

Uski, S.. \& Lampinen, A. (2014). Social norms and self-presentation on social network sites: Profile work in action. New Media \& Society, Vol 18, Issue 3, pp. 447-464. https://doi.org/10.1177/1461444814543164

Van Zoonen, L. (2013). From identity to identification: Fixating the fragmented self. Media, Culture and Society 35(1), 44-51. https://doi.org/10.1177/0163443712464557

Vygotsky, L. S. (1998). The problem of age (M. Hall, Trans.). In R. W. Rieber (Ed.), The collected works of L. S. Vygotsky: Vol. 5. Child psychology (pp. 187-205). New York: Plenum Press. (Original work written 1933-1934).

White, R. (2016). Youth Gangs, Violence and Social Respect: Exploring the Nature of Provocations and Punch-ups. Palgrave MacMillan.

Wilson, C. J., \& Deane, F. P. (2010). Help-negation and suicidal ideation: The role of depression, anxiety, and hopelessness. Journal of Youth and Adolescence, 39, 291-305. https://doi.org/10.1007/s10964-009-9487-8

Wolfe, S. E., Marcum, C. D., Higgins, G. E., \& Ricketts, M. L. (2014). Routine cell phone activity and exposure to text messages: Extending the generality of routine activity theory and exploring the etiology of a risky teenage behavior. Crime \& Delinquency, 62(5), 614 - 644. https://doi.org/10.1177/0011128714541192

Zorrilla, B., Pires, M., Lasheras, L., Morant, C., Seoane, L., Sanchez, L., \& Durbán, M. (2010). Intimate partner violence: Last year prevalence and association with socio-economic factors among women in Madrid, Spain. European Journal of Public Health, 20(2), 169-175. https://doi.org/10.1093/eurpub/ckp143

Zotova, L. E., Prjazhnkikov, N. S., Berezhnaja, M. S., Ermakov, V. A., \& Melamud, M. R. (2016). Specific features of life situations in teenagers and young people, predisposed to deviant behavior. International Journal of Environmental \& Science Education, 11(18), 11889-11897. Retrieved from https://files.eric.ed.gov/fulltext/EJ1121773.pdf

\section{Copyrights}

Copyright for this article is retained by the author(s), with first publication rights granted to the journal.

This is an open-access article distributed under the terms and conditions of the Creative Commons Attribution license which permits unrestricted use, distribution, and reproduction in any medium, provided the original work is properly cited. 